\title{
AS MÚLTIPLAS LINGUAGENS NA EDUCAÇÃO INFANTIL
}

\section{ARTIGO ORIGINAL}

PATTUZZO, Yngrid Galimberti ${ }^{1}$, GONÇALVES, Éllida dos Santos²

PATTUZZO, Yngrid Galimberti. GONÇALVES, Éllida dos Santos. As múltiplas linguagens na Educação Infantil. Revista Científica Multidisciplinar Núcleo do Conhecimento. Ano 04, Ed. 08, Vol. 01, pp. 53-71. Agosto de 2019. ISSN: 2448-0959, Link de acesso: https://www.nucleodoconhecimento.com.br/educacao/multiplaslinguagens, DOI: 10.32749/nucleodoconhecimento.com.br/educacao/multiplaslinguagens

\section{RESUMO}

Este trabalho tem como objetivo mapear as múltiplas linguagens presentes no cotidiano de um Centro de Educação Infantil (CEI) localizado no Município de Vitória - ES. Concomitantemente busca compreender como essas linguagens potencializam as aprendizagens e o desenvolvimento das crianças. Sendo de caráter exploratório de cunho qualitativo, a pesquisa utiliza como procedimentos metodológicos: entrevistas semiestruturadas e observação do cotidiano das crianças com registro em um diário de campo. Como referencial teórico, utiliza Vigotski (2000), entre outros autores com os estudos voltados para o estudo de infância e educação infantil. Mediante a pesquisa é possível afirmar que as múltiplas linguagens contribuem muito para o desenvolvimento.

Palavras-chave: Múltiplas linguagens, educação infantil, crianças.

\footnotetext{
${ }^{1}$ Pós graduação na área da Educação Especial e Gestão Educacional, graduação em Pedagogia realizada na UFES.

${ }^{2}$ Formada em Pedagogia pela Universidade Federal do Espírito Santo. Pós-graduanda em Alfabetização e Letramento.
}

RC: 35237

Disponível em: https://www.nucleodoconhecimento.com.br/educacao/multiplaslinguagens 


\section{INTRODUÇÃO}

As cores, as imagens, os desenhos e os sons estão presentes em nossa vida desde o nascimento, e isso não é diferente no ambiente escolar, principalmente na educação infantil. Nesse período, as crianças utilizam abundantemente essas linguagens para se expressarem. Expressam-se quando cantam, quando preenchem uma folha com cores, nas brincadeiras, nos movimentos, ao aprenderem algo novo, na sua relação com os colegas e com os (as) professores (as).

O uso das diversas linguagens pelas crianças está previsto nos documentos que normatizam as práticas pedagógicas na educação infantil. Exemplo disso são as Diretrizes Curriculares Nacionais para Educação Infantil (DCNEI), que estabelecem princípios de ação tomando por base o conceito de criança e de currículo. Esses princípios concorreram para ampliar o debate presente na Base Nacional Comum Curricular (BNCC) $)^{[3]}$ e estabeleceram seis direitos de aprendizagens que devem ser garantidos na Educação Infantil: conviver, brincar, participar, explorar, expressar e conhecer-se.

Expressar-se como sujeito criativo e sensível, com diferentes linguagens, sensações corporais, necessidades, opiniões, sentimentos e desejos, pedidos de ajuda, narrativas, registros de conhecimentos elaborados a partir de diferentes experiências, envolvendo tanto a produção de linguagens quanto a fruição das artes em todas as suas manifestações (BRASIL, 2016, p.62).

Portanto, é necessário e imprescindível que o direito da criança de se manifestar em suas múltiplas linguagens seja garantido nas práticas pedagógicas desenvolvidas nas escolas de educação infantil. Contudo, não são raras as ocasiões em que essas crianças encontram certa resistência às suas manifestações expressivas (desenhos, pinturas, esculturas, movimentos, brincadeiras, falas), nem sempre compreendidas pelas instituições pré-escolares ou creches que frequentam.

Diante disso, se faz necessário entender que as múltiplas linguagens estão presentes no cotidiano escolar e que, sobretudo na vida da criança, são tão importantes quanto a linguagem escrita. Além disso, quando aliadas ao trabalho pedagógico em sala de 
aula, tais práticas de linguagem proporcionam aprendizagens significativas na vida da criança. Considerando tais fatos, este estudo tem o objetivo de investigar e mapear as múltiplas linguagens no cotidiano da educação infantil e como o uso dessas pelos (as) professores (as) podem potencializar a aprendizagem da criança.

\subsection{JUSTIFICATIVA}

O tema desse estudo foi escolhido a partir do interesse em entender como uma escola de educação infantil utiliza as múltiplas linguagens para o ensino do (a) aluno (a) e, mostrando a importância de oportunizar a expressão das múltiplas linguagens das crianças, como a utilização dessas pode potencializar a aprendizagem.

\subsection{OBJETIVOS}

- Problema de Pesquisa: Como e quais as linguagens estão presentes no cotidiano de uma instituição de educação infantil?

- Objetivo Geral: Mapear/identificar quais as linguagens estão presentes nas práticas pedagógicas desenvolvidas na escola de educação infantil.

- Objetivos Específicos:

1. Fazer um mapeamento das linguagens que mais são utilizadas pelas professoras em suas práticas pedagógicas;

2. Identificar os projetos/atividades desenvolvidos com as crianças pelas professoras e perceber como as linguagens permeiam as ações vinculadas aos projetos e atividades;

3. Compreender como os professores utilizam as múltiplas linguagens no cotidiano de suas práticas;

4. Analisar como a utilização das múltiplas linguagens interfere no desenvolvimento das crianças. 


\section{REFERENCIAL TEÓRICO}

Para a base desta pesquisa, utilizaremos as concepções teóricas de Vigotski (2000) e suas contribuições nos estudos sobre como se desenvolvem o pensamento e a linguagem; como literatura de referência nos campos de estudo das múltiplas linguagens, utilizaremos Edwards, Gandini e Forman (1999); e, nas especificidades dos estudos da infância e educação infantil, Corsino (2009) e Faria e Finco (2011).

Como nos informam Faria e Finco (2011, p. 21),

A criança é ao mesmo tempo universal, individual e singular. Mas a criança é devir, um futuro que ainda não está e não é, uma criança que nasce traz em si esse futuro, ela é o tempo intempestivo, o tempo de ruptura, a fratura, a descontinuidade daquilo que não sabemos, não somos, não está, estamos em via de nos deferir, e que será inventado.

Portanto, em virtude desse aspecto sempre novo da infância, são necessárias investigações com o intuito de reinventar a educação que está sendo oferecida às crianças. Como afirma Corsino, "são necessários estudos, reflexões e articulações entre teoria e prática” (2009, p. 2).

Sendo assim, é impossível cogitar e criar diálogos sobre os alunos da El sem pensar nas múltiplas linguagens, pois "um trabalho de educação infantil que tem as manifestações infantis e as interações como centro de sua proposta não pode deixar de considerar a linguagem como eixo que perpassa todas as instâncias." (CORSINO, 2009, p. 7). Isso se dá porque as múltiplas linguagens são parte integrante na criança. Edwards, Gandini e Forman (1999) apontam a importância das múltiplas linguagens para o desenvolvimento infantil da seguinte maneira:

As crianças pequenas são encorajadas a explorar seu ambiente e a expressar a si mesmas através de todas as suas "linguagens" naturais ou modos de expressão, incluindo palavras, movimento, desenhos, pinturas, montagens, escultura teatro de sombras, colagens, dramatizações e música (EDWARDS; GANDINI; FORMAN, 1999, p. 21). 
Portanto, fica clara a grande utilização das múltiplas linguagens desde o nascimento. Consequentemente, as expressões das crianças através das múltiplas linguagens não devem se perder na Educação Infantil, pois

Desde que vem ao mundo, o bebê interage de diferentes maneiras no ambiente físico e social que o cerca. Entretanto, seu ingresso em uma instituição de caráter educativo o fará experimentar, forçosamente e de forma sistemática, situações de interação distintas das que vive em sua família (MACHADO, 2004, p.26).

Neste contexto, podemos agregar as contribuições de Vigotski (2000) que, a partir de sua teoria histórico-cultural, afirma que a aprendizagem ocorre por meio das interações sociais. Sabemos que o desenvolvimento das linguagens nas crianças também ocorre por meio dessas interações. Em sua obra $A$ Construção do Pensamento e da Linguagem (2000), o teórico mostra questões fundamentais do pensamento infantil na aquisição das linguagens.

Vigotski a todo o momento fala do pensamento junto à linguagem. Ele afirma que, diante de vários trabalhos realizados com estes temas, sempre houve duas posições principais: por um lado, a "plena identificação e a plena fusão do pensamento" com a linguagem, por outro, "a plena dissociação" de tais termos. No contexto psicológico, de acordo com o autor, pensamento e linguagem sempre andaram juntos.

Desde a antiguidade, a identificação do pensamento com a linguagem, tanto na linguística psicológica - segundo a qual pensamento é "linguagem menos som" - quantos nos atuais psicólogos e reflexólogos americanos - para quem o pensamento é um "reflexo inibido não revelado em sua parte motora" - , conheceu uma linha única de desenvolvimento de uma mesma ideia, que identifica o pensamento com a linguagem (VIGOTSKI, 2000, p. 3).

Diante disso, é relevante pautar a concepção de Vigotski sobre o que é a linguagem. Para o teórico,

A linguagem é, antes de tudo, um meio de comunicação social, de enunciação e compreensão. Também na análise, que se decompunha em elementos, essa função da linguagem se dissociava da sua função intelectual, e se atribuíam ambas as funções a linguagem como se fossem paralelas e independentes uma da outra (VIGOTSKI, 2000, p. 11). 
Sendo assim, todos os tipos de linguagens, tanto musical, verbal, escrita, pictográfica, visual, são formas de comunicação social. As crianças possuem, por isso, diversas formas de se comunicarem, se expressarem, mostrarem os seus desejos, seja entre elas ou com os adultos. Partimos, portanto, do pressuposto que as linguagens estão presentes e são essenciais na Educação Infantil e de que é tarefa de todos os profissionais que estão diretamente e/ou indiretamente ligados à educação da criança possibilitar as diferentes manifestações das linguagens. Assim sendo, devem permitir a expressão das diferenças e promover processos de diálogo e negociação através das trocas e comparação de ideias. Dessa forma, as múltiplas linguagens existentes nas crianças devem ser exploradas de todas as maneiras possíveis pois exercem papéis importantes na aprendizagem das mesmas e são relevantes para o desenvolvimento e crescimento delas.

Se por um lado o professor tem o dever de garantir as múltiplas linguagens na educação infantil, por outro o ambiente escolar também tem um papel essencial na consolidação delas. O espaço escolar precisa possibilitar a criança a se expressar em suas múltiplas linguagens, pois,

O ambiente é visto como algo que educa a criança; na verdade, ele é considerado o "terceiro educador" juntamente com a equipe de dois professores. A fim de agir como educador para a criança, o ambiente precisa ser flexível; deve passar por uma modificação frequente pelas crianças e pelos professores a fim de permanecer atualizado e sensível às suas necessidades de serem protagonistas na construção de seu conhecimento. Tudo o que cerca as pessoas na escola e o que usam - os objetos, os materiais e as estruturas - não são vistos como elementos cognitivos passivos, mas, ao contrário, como elementos que condicionam e são condicionados pelas ações dos indivíduos que agem nela (EDWARDS; GANDINI; FORMAN, 1999, p. 157).

$\mathrm{Na}$ escola, todos os aspectos devem estar favorecendo o desenvolvimento dessas diferentes linguagens nos alunos, desde o ambiente escolar, como já citado, passando pelos professores, pelas atividades realizadas, pelas relações, enfim, tudo que os rodeiam neste ambiente. Dessa forma, as unidades de educação precisam voltar-se para o ensinar buscando envolver as múltiplas linguagens em seus trabalhos. 


\section{PROCEDIMENTOS METODOLÓGICOS}

Para alcançar os objetivos que este estudo se propôs, a presente pesquisa teve caráter exploratório e descritivo, sendo ela também qualitativa, pois são apresentados tanto dados objetivos como também subjetivos. Entende-se como pesquisa exploratória,

[...] quando o domínio de investigação não é bem conhecido do pesquisador, a ponto de este julgar preferível não elaborar hipótese a priori. Esta é então simultaneamente desenvolvida e verificada, ainda que em parte, em um vaivém entre reflexão, observação e interpretação, à medida que a análise progride (LAVILLE; DIONNE, 1999, p. 228).

Entendemos que o método exploratório atende a nossa pesquisa, pois com este método podemos dispor de vários instrumentos para a análise de dados. Portanto, utilizamos esses métodos de pesquisa aplicados por meio de instrumentos para a obtenção dos dados: a) entrevistas semi estruturadas com os (as) professores (as) e os (as) pedagogos (as) da instituição pesquisada e b) a observação do cotidiano das crianças com consequente produção de um diário de campo.

A pesquisa de campo aconteceu em um Centro de Educação Infantil (CEI) localizado no Município de Vitória. O CEI atende 135 crianças de 2 a 5 anos, distribuídas em quatro turmas no período do matutino e três turmas no período vespertino. No turno matutino, são contemplados (as) alunos (as) de 2 a 5 anos e, no vespertino, alunos (as) de 3 a 5 anos. Em todos os casos, as crianças são acompanhadas por professor (a), auxiliar e monitor (a).

Os sujeitos da pesquisa foram 4 professores (as), o pedagogo e as crianças do grupo três, quatro e cinco da instituição. Além da observação e registro de diário de campo, também foi realizada com os (as) professores (as) uma entrevista semi estruturada.

\section{ANÁLISE DE DADOS}

Para a organização e desenvolvimento da análise dos dados deste trabalho, estruturamos o texto em três categorias. A primeira categoria trata de mapear as

RC: 35237

Disponível em: https://www.nucleodoconhecimento.com.br/educacao/multiplaslinguagens 
linguagens presentes no cotidiano, descrevendo minuciosamente o que observamos e relatamos no diário de campo sobre a manifestação das linguagens pelas crianças na educação infantil. Na segunda categoria, procuramos apresentar o trabalho que o (a) professor (a) realiza abordando as múltiplas linguagens em conjunto com seus alunos. Na terceira e última categoria, empenhamo-nos em entender como as linguagens potencializam a aprendizagem da criança.

\section{MAPEANDO AS LINGUAGENS PRESENTES NO COTIDIANO DA EI}

Neste tópico objetivamos apresentar e analisar a primeira categoria que foi proposta nesta pesquisa. Discorremos, portanto, sobre as linguagens presentes no cotidiano da educação infantil, descrevendo minuciosamente o que observamos e relatamos no diário de campo sobre a manifestação das linguagens pelas crianças. Sendo assim, a partir das falas dos (as) entrevistados (as), produzimos, com o intuito de mapear as linguagens presentes com mais ênfase no cotidiano da instituição, o seguinte quadro:

Quadro 1 - Mapeamento das linguagens utilizadas pelas crianças

\begin{tabular}{|l|c|c|c|c|c|}
\hline LINGUAGENS & $\begin{array}{c}\text { PROF. (A) } \\
\text { G3 }\end{array}$ & $\begin{array}{c}\text { PROF. (A) } \\
\text { G4 }\end{array}$ & $\begin{array}{c}\text { PROF. (A) } \\
\text { G5 }\end{array}$ & $\begin{array}{c}\text { PROF. (A) } \\
\text { ED. } \\
\text { FÍSICA }\end{array}$ & $\begin{array}{c}\text { PEDAGO } \\
\text { GO }\end{array}$ \\
\hline CORPORAL & & & & & \\
\hline PICTOGRÁFICA & & & & & \\
\hline MUSICAL & & & & & \\
\hline ESCRITA & & & & & \\
\hline ORAL & & & & & \\
\hline VISUAL & & & & & \\
\hline
\end{tabular}

Linguagens citadas pelos (as) entrevistados (as). Linguagens não citadas pelos (as) entrevistados (as).

Fonte: organização das autoras.

RC: 35237

Disponível em: https://www.nucleodoconhecimento.com.br/educacao/multiplaslinguagens 
O gráfico apresentado nos proporciona observar a supremacia da linguagem oral, visto que todos os (as) entrevistados (as) a citaram como linguagem mais frequente no aluno. Em relação a essa centralidade da linguagem oral, Corsino $(2009$, p. 50) destaca a importância das palavras. Segundo a autora,

As palavras servem para brincar, para rir, para chorar, para expressar sentimentos e desejos, para convencer, para ordenar, para informar, para aprender e ensinar, para comunicar-se com o outro, para pensar. A linguagem é um instrumento de ação no mundo, sobre o outro e com os muitos outros que constituem o nosso pensamento e a nossa consciência.

Depois da linguagem oral, a linguagem corporal foi uma das mais citadas, visto que realmente é explícita a frequência desta linguagem, já que as crianças estão constantemente em movimento. Elas brincam, pulam, correm e, por meio de tais movimentos, se expressam. Entendemos que também há grande importância desta linguagem na educação infantil, visto que:

O movimento para a criança pequena significa muito mais do que mexer partes do corpo ou deslocar-se no espaço. A criança se expressa e se comunica por meio dos gestos e das mímicas faciais e interage utilizando fortemente $o$ apoio do corpo. A dimensão corporal integra-se ao conjunto da atividade da criança. $\mathrm{O}$ ato motor faz-se presente em suas funções expressivas, instrumental ou de sustentação às posturas e aos gestos (BRASIL, 1998, p.18)

Por outro lado, observamos que as linguagens musicais e escritas foram citadas com menos frequência. A escrita é presente na educação infantil, contudo não recebe tanta ênfase no contexto pesquisado pelo fato de as crianças ainda não estarem integralmente alfabetizados. Cabe ressaltar, porém, que, ao refletirmos sobre a alfabetização na educação infantil, é importante ter em mente que:

[...] a educação infantil não é uma etapa que tem como preocupação enfatizar 0 trabalho com a linguagem escrita em detrimento de outras para que as crianças adiantem a alfabetização e cheguem ao ensino fundamental "mais preparadas". Acreditamos, contudo, que o processo de alfabetização se inicie na educação infantil e que o mesmo será continuado e ampliado nos primeiros anos do ensino fundamental. (PPP DA INSTITUIÇÃO PESQUISADA, 2016 2017, p. 117)

Fica evidente que a linguagem escrita é presente no cotidiano das crianças, contudo ela não é e nem deve ser hipervalorizada em detrimento das demais linguagens.

RC: 35237

Disponível em: https://www.nucleodoconhecimento.com.br/educacao/multiplaslinguagens 
Apesar de a expressão artística ser pouco citada pelos sujeitos entrevistados, observamos que a pictográfica é muito recorrente. De fato, na educação infantil esta expressão está muito presente.

Em nossas observações, percebemos que todas as linguagens postas no quadro são manifestadas no cotidiano da escola pesquisada, contudo entendemos que muitas linguagens não foram citadas pelos professores no quadro, pois este se trata da linguagem que a criança mais utiliza. Esta análise nos possibilitou, portanto, inferir que a linguagem oral é a mais utilizada pelas crianças nas aulas.

\subsection{O TRABALHO QUE O (A) PROFESSOR (A) REALIZA UTILIZANDO AS MÚLTIPLAS LINGUAGENS COM SEUS (SUAS) ALUNOS (AS)}

No tópico anterior, tivemos como objetivo realizar um mapeamento das linguagens presentes no cotidiano da educação infantil. Se antes as descrevemos, neste tópico propomos relatar e analisar o trabalho dos professores utilizando essas linguagens. $\mathrm{Na}$ escola pesquisada, os professores trabalham com projetos institucionais. No ano de 2017, o projeto teve o objetivo de "conhecer a turma da Mônica, e o Maurício de Souza, a principal obra do Mauricio de Souza, que é a Turma da Mônica" (PROFESSORA DO GRUPO 4). De acordo com o PPP, todos os projetos desenvolvidos no CEl têm um ponto de partida em comum:

\footnotetext{
O trabalho com projetos é uma das práticas docentes desenvolvida no CEI [...]. Ele tem sua gênese a partir do interesse e necessidades sinalizadas pelas crianças. Após um período de observação de situações vividas no cotidiano e atravessadas pela sensibilidade do professor, propostas são lançadas às crianças e essas, com suas respostas, dão o tom e o sabor ao que será produzido no coletivo. Diante do "desconhecido", os professores passam por provoca-ações diante de tantas questões levantadas pelas crianças. São dúvidas, curiosidades, conhecimentos e muitas hipóteses e descobertas que serão (des)construídas a medida do desenvolvimento do trabalho (PPP DA INSTITUIÇÃO PESQUISADA, 2016 - 2017, p. 74).
}

Portanto, os professores e a gestão escolar decidem o projeto que irá ser trabalhado pela instituição naquele determinado ano e, a partir da temática escolhida, cada professor tece seu projeto junto a seus alunos. Em relação à perspectiva de

Disponível em: https://www.nucleodoconhecimento.com.br/educacao/multiplaslinguagens 
organização da prática pedagógica por meio de projetos, Barbosa e Horn (2008, p. 31) afirmam que:

Os projetos permitem criar, sob forma de autoria singular ou de grupo, um modo próprio para abordar ou construir uma questão e respondê-la. A proposta de trabalho com projetos possibilita momentos de autonomia e independência do grupo; momentos de cooperação do grupo sob uma autoridade mais experiente e também de liberdade; momentos de individualidade e de sociabilidade; momentos de interesse e de esforço; momentos de jogo e de trabalho que expressam a complexidade do trabalho educativo.

Entendemos que, apesar de o projeto institucional ser único, cada professor precisa adaptá-lo aos interesses de seus alunos, pois as crianças são diferentes e possuem demandas diversas. $\mathrm{Na}$ escola pesquisada, cada professor (a) desenvolveu uma abordagem específica do tema, adaptando-o para a demanda de seu grupo. Essas abordagens, assim como as linguagens exploradas em cada uma delas, podem ser resumidas da seguinte forma:

A professora do grupo 3 desenvolveu o projeto intitulado "Tem bicho de todo jeito: conhecendo e aprendendo sobre os animais". Inicialmente, esse tema parece não ter ligação com o projeto institucional, contudo, durante a pesquisa, especificamente nos momentos de observação, identificamos que o trabalho realizado pela professora articulou o tema proposto com os interesses de seus alunos e alunas. Durante as observações, na realização do projeto, é importante ressaltar as linguagens trabalhadas que estavam explícitas nessas atividades, pois, por meio delas, o aluno tem o contato com a linguagem visual, linguagem oral, linguagem corporal, pictográfica entre outras.

A professora realizou um trabalho sobre os animais através de várias linguagens, tornando-o significativo para as crianças. Durante o desenvolvimento deste projeto, foram trabalhadas a linguagem oral, que é parte integrante na vida dos alunos e alunas, uma vez que estes se comunicavam, participavam de contações de histórias; a linguagem visual, desenvolvida através das imagens, filmes e vídeos sobre a temática do projeto e demais recursos visuais na escola; e a linguagem pictográfica, 
a partir da produção de desenhos. A linguagem musical também se mostrou presente no cotidiano das crianças do Grupo 3 da instituição pesquisada.

Com relação ao Grupo 4, o projeto desenvolvido foi denominado "Tudo sobre mim". Esse projeto foi descrito pela professora responsável da seguinte maneira:

A gente está trabalhando no projeto "Tudo sobre mim", o projeto institucional desse ano é conhecer a turma da Mônica, e o Maurício de Souza, a principal obra do Mauricio de Souza, que é a Turma da Mônica, e ai a gente pensou que antes de conhecer o Maurício de Souza é importante que a gente se conheça. Então, o nome do nosso projeto é "Tudo sobre mim", e o nosso objetivo é, em linhas gerais né, que o projeto institucional, prestigiará este ano o cartunista brasileiro Maurício de Souza e a Turma da Mônica, sua principal obra, para tanto, entendemos que, antes de conhecermos o Maurício de Souza e sua obra é necessário que pesquisemos e aprofundemos o conhecimento sobre nós mesmos e o outro. (PROFESSORA DO GRUPO 4)

A professora percebeu a importância de o aluno conhecer a si mesmo, por isso iniciou um trabalho que propiciasse o autoconhecimento. Esse é um tema muito relevante na educação infantil, pois a criança está em um momento privilegiado para descobertas e aprendizados. Nesse processo, é muito importante que ela (re)conheça a si mesma. Durante a observação vimos o fato de que a docente inicia o projeto com a intenção de desenvolver um conhecimento do (a) aluno (a) sobre si, mas logo revela outros caminhos que foram trilhados no decorrer do projeto. Exemplo disso é o trabalho sobre o cuidado com o outro e com o meio ambiente, considerado quase uma consequência das atividades de reconhecimento de si. Destacamos as linguagens oral, visual e corporal presentes durante o dia a dia das crianças da instituição pesquisada. Elas faziam uso constante das múltiplas linguagens nas brincadeiras e atividades propostas pela professora, como contação de histórias e encenações, assim como durante a roda, no pátio, etc.

Com relação ao projeto desenvolvido no grupo 5, a professora esclarece que:

Nós estamos agora neste retorno das férias, realizando um trabalho que começamos no início do semestre que tem a ver com a história da escrita, com a história dos números e nós trabalhamos com o alfabeto. As crianças levaram um bichinho que nos pedimos para fazer que se chama: "bichinho diferente" a partir da poesia da Priscila Ramos e aí as crianças levaram que na patinha dele

RC: 35237

Disponível em: https://www.nucleodoconhecimento.com.br/educacao/multiplaslinguagens 
tem todas as letras. Antes do alfabeto, trabalhamos a história da escrita, dos símbolos e agora estamos trabalhando diferentes tipos de letras, mostrando pra eles não para que eles aprendam a escrever esses diferentes tipos de letras, mas mostrando que não tem só a letra bastão, mostrando a existência delas, estamos trabalhando com o livro do Millôr Fernandes, as letras de diferentes formas, ele traz assim de uma forma lúdica e engraçada para as crianças e ai as crianças na semana passada elas fizeram desenhos, que nesses desenhos a letras faziam parte, por exemplo, uma criança fez um super herói com martelo e o martelo era a letra T com massinha, então é isso que estamos desenvolvendo e nessa semana, também vamos fazer uma decoração de letras, e seria isso.[...] (PROFESSORA DO GRUPO 5)

Observamos que a inserção dos (as) alunos (as) do grupo 5 na alfabetização é realizada de forma lúdica e criativa. Consequentemente, a criança demonstra um interesse maior e isso gera maior desenvolvimento no seu processo de aprendizagem. Além disso, é interessante notar que a professora não partiu diretamente apenas para o ensino das letras, suas diferentes formas e como são escritas; antes disso, ela trabalhou com as crianças a história da escrita e dos símbolos, oferecendo, assim, um conhecimento mais amplo a respeito, expondo como existiu a escrita e por que.

Este processo de aprendizagem, como desenvolvido pela professora do grupo 5 no referido projeto, foi realizado de forma interessante e divertida, pois era nítida a presença, além da linguagem escrita, também da pictográfica e a modelagem com massinhas, pois observamos que as crianças aprenderam as letras também por meio do desenho e da modelagem com massinha.

A professora de Educação Física, por sua vez, desenvolveu um projeto diferente e muito interessante com as crianças: a Capoeira. Essa atividade é uma mistura de dança e esporte que tem um grande peso cultural. Dessa forma, as crianças não aprendem somente a dança, mas também a diversidade cultural. A respeito do projeto, a professora relatou que: "A capoeira é um meio para desenvolver essa criança em movimento no mundo, pra elas se entenderem quanto serem um corpo no mundo, então assim, e a partir daí a gente utilizou a capoeira." Vale ressaltar que tal projeto possui um conteúdo muito amplo. Além da demonstração de diversidade cultural, por meio dele as crianças também potencializam a linguagem corporal, bem como 
também a musical, pois, ao mesmo tempo em que reproduzem os movimentos, há presença das músicas.

[...] são as especificidades da capoeira, a musicalização, a interação, o limite, os movimentos vertidos, né, aí são as especificidades que vem da capoeira, né, agora a capoeira na escola, ela traz outros objetivos também, que tá ligada a essa criança no mundo, movimentar-se no mundo [...] (PROFESSORA DE EDUCAÇÃO FíSICA)

Sendo assim, tal projeto respalda fatores importantes, como citados pela professora: a musicalização, a interação, os movimentos, todos eles muito significativos para o desenvolvimento das crianças. Ainda, possibilita trabalhar com diversidade cultural, o projeto voltado à prática da capoeira. Dessa forma, além de entendermos o funcionamento dos projetos buscamos também entender, a partir de questões colocadas para os próprios docentes da instituição pesquisada, quais seriam os desafios para que as crianças possam ter espaço para se manifestarem. De acordo com a professora do Grupo 3,

Os desafios do trabalho com as linguagens na escola envolvem o planejamento do professor, grupos de estudo sobre a temática entre os professores e reuniões de pais que abordem a temática visando ampliar por meio das interações e brincadeiras, diferentes experiências e aprendizagens no cotidiano da educação infantil.

São evidentes os desafios no trabalho com as múltiplas linguagens com as crianças. É necessário planejamento do (a) professor (a) para que ele (a) possa projetar suas aulas de forma que abarque variadas linguagens, sem ressaltar apenas uma ou duas, fato que pudemos observar em algumas práticas dos docentes. No entanto, às vezes, os desafios podem partir das próprias crianças, pois elas podem se interessar em apenas algumas específicas linguagens.

A mediação é um processo essencial e uma relação social que interfere de forma direta no desenvolvimento das crianças. A esse respeito, Vigotski $(2000$, p. 79$)$ diz que "o biológico é concebido como primário, fundante, que está contido na própria criança e forma a sua substância psicológica. O social age através da coação como uma força exterior, estranha à criança [...]". O funcionamento psicológico se 
fundamenta nas relações sociais entre os indivíduos. Sendo assim, a figura do professor mediador nos processos educacionais é de fundamental importância para qualificar as aprendizagens das crianças.

\title{
5.1 COMO AS MÚLTIPLAS LINGUAGENS POTENCIALIZAM A APRENDIZAGEM DAS CRIANÇAS NA EDUCAÇÃO INFANTIL
}

Nas categorias anteriores, dialogamos sobre as linguagens presentes na El e os projetos desenvolvidos pelos professores por meio das múltiplas linguagens. Entendemos que a presença destas é de suma importância no cotidiano da criança. Sendo assim, esta última categoria da análise de dados pretende expor como o uso das múltiplas linguagens pode potencializar a aprendizagem e o desenvolvimento das crianças. Para iniciar nossa análise, vamos considerar a fala da professora do grupo 4 a respeito da importância das múltiplas linguagens na educação infantil.

\begin{abstract}
[...] a gente se manifesta de diversas formas, pelo choro, pelo olhar e de diversas outras formas. Além disso, o homem, por meio do trabalho ele produz diversos elementos, que tem a ver com aquilo que te apresentei, na sua relação com a natureza ele vai produzir os bens materiais e os bens simbólicos, aí entra todo mundo da linguagem escrita, artes, tudo que você imagina, das tecnologias, né, que elas vão tomando contornos diferentes com o passar do tempo e diante com as necessidades que a gente tem, então, com certeza, eu acho que potencializa, mas o que potencializa não é só a apresentação, mas a mediação qualificada, ali você se apropriando de alguns conceitos, esses conceitos se relacionam com a prática, essa mediação é que vai potencializar, o professor, o monitor, o estagiário, que a interação que a gente tem com a criança ali vai. (PROFESSORA DO GRUPO 4)
\end{abstract}

A professora coloca em relevo a importância das linguagens na aprendizagem das crianças, ressaltando a mediação do docente neste processo. De fato, para que ocorra esta potencialização é necessária uma intervenção qualificada. $O$ (a) professor (a) deve preocupar-se, nas suas práticas, em procurar abarcar diversas linguagens, sem valorizar apenas uma e esquecendo as outras. Nesta questão de valorização de uma única linguagem, vale mencionar que é normal uma ou duas linguagens se destacarem mais ou serem mais utilizadas pelas crianças. No entanto, as outras linguagens não devem ser esquecidas, visto que todas contribuem para a evolução das crianças em inúmeros aspectos.

RC: 35237

Disponível em: https://www.nucleodoconhecimento.com.br/educacao/multiplaslinguagens 
Em síntese, os (as) professores (as), de um modo geral, evidenciaram que um trabalho pedagógico que abarque as múltiplas linguagens potencializa a aprendizagem da criança, pois, quando tem a oportunidade de se expressar em suas múltiplas linguagens durante as atividades nos momentos sala de aula, com os colegas, ou em qualquer outro ambiente da escola, ela consegue vivenciar novas experiências que ampliam seus conhecimentos. Como bem destacam Costa e Santos,

As múltiplas linguagens são de fundamental importância, pois contribuem no desenvolvimento integral da criança oportunizando a elas novas vivências, como se expressar melhor e explorar mais o ambiente no qual está inserida. As crianças precisam vivenciar novas experiências no espaço de educação infantil, ter oportunidade de desenvolver diferentes formas de sentir, pensar e solucionar problemas. (COSTA; SANTOS, 2017, p.716)

É necessário, portanto, dar espaço às crianças para vivenciarem as suas múltiplas linguagens, pois estas "[...] ampliam o trabalho pedagógico, contribuem para o desenvolvimento integral da criança oportunizando-a a novas vivências e experiências" (COSTA; SANTOS, 2017, p.716). Assim, faz-se imprescindível compreender que a potencialização do conhecimento pelo uso das múltiplas linguagens só acontecerá se houver a presença de um trabalho voltado para a utilização dessas linguagens (oral, escrita, pictográfica, musical, corporal, teatral, visual) na escola. No entanto, para que ocorra essa potencialização, a intervenção do (a) professor (a) é importante. Como argumenta Vigotski,

Aqui devemos aplicar o conceito de convergência: a conquista da linguagem pela criança só ocorre na interação permanente entre os rudimentos interiores, em que já existe atração pela linguagem, e as condições externas configuradas na linguagem das pessoas que rodeiam a criança, que dá a esses rudimentos o impulso à aplicação e material para sua realização. (VIGOTSKI, 2000, p.108)

As crianças já nascem com um equipamento biofisiológico predisposto à aprendizagem e à manifestação das múltiplas linguagens, no entanto, o avanço das mesmas ocorre devido a fatores externos, por meio das relações e da socialização. Esse fato torna a ação docente de extrema relevância, pois o professor atuará garantindo um ambiente de socialização que potencializa ou o contrário, essas 
manifestações. Podemos evidenciar, em nossas observações, que o uso das múltiplas linguagens nas atividades participa da aprendizagem dos alunos.

\section{CONSIDERAÇÕES FINAIS}

Nosso estudo se direcionou a pesquisar as linguagens que as crianças expressam no cotidiano da Educação Infantil. Malaguzzi (1994) defende que as crianças possuem "cem linguagens". Durante nossas observações, isso se evidenciou o tempo todo. Nos diferentes espaços e tempos, as crianças se expressam pela fala, pelos movimentos, enquanto brincam, nas atividades direcionadas ou livres e no pátio. Assim, entendemos que a educação infantil é um espaço privilegiado para a expressão das múltiplas linguagens da criança. Portanto, faz-se necessário pensar na rotina, no espaço físico, nas atividades que propiciem a expressão das crianças através de suas múltiplas linguagens.

A partir das análises das entrevistas, observações e relatos no diário de campo, percebemos que os (as) professores (as) se mostram dispostos a realizar um trabalho que contemple as múltiplas linguagens, pois entendem que a criança é feita delas. Por essa razão, a questão é pensada no planejamento das aulas e na realização das atividades.

A temática que pesquisamos é muito abrangente, por isso ainda há muitas questões a serem exploradas no campo. Buscamos mapear as múltiplas linguagens e mostrar a influência que um trabalho pautado nestas podem ter no desenvolvimento e aprendizagem da criança. Contudo, ainda há outros caminhos que não conseguimos percorrer no presente estudo.

\section{REFERÊNCIAS}

ALMEIDA, R.P.W. Infância e educação infantil: o grupo de crianças e suas ações em contexto escolar. Trabalho apresentado na 34를 Reunião Anual da ANPEd, Natal, 2011.

RC: 35237

Disponível em: https://www.nucleodoconhecimento.com.br/educacao/multiplaslinguagens 
ALVES, Bruna Molisani Ferreira. Linguagem e educação infantil: o que contam as professoras sobre o trabalho pedagógico ?. Trabalho apresentado no GT 07. Anais da 37ª Reunião Científica da ANPEd, Florianópolis, 2015. Disponível em $<$ https://play.google.com/store/apps/details?id=dmx.appyou.anped37>. Acesso em: 12 dez. 2017.

BARBOSA, M.C.S.; HORN, M.G.S. Projetos pedagógicos na Educação Infantil. Porto Alegre: Artmed, 2008.

BERLE, Simone. Infância e linguagem: educar os começos. Trabalho apresentado no GT 07. Anais da 36 Reunião Científica da ANPEd, Goiânia, 2013. Disponível em $<$ http://www.anped.org.br/sites/default/files/gt07_3422_texto.pdf>. Acesso em: 12 dez. 2017.

BEZERRA, P. Prólogo do tradutor. In: VIGOTSKI, Lev Semionovich. A construção do Pensamento e da Linguagem. São Paulo: Martins Fontes, 2000. p. vii-xiv.

BRASIL. Ministério da Educação. Base Nacional Comum Curricular. Proposta preliminar. Segunda versão revista. Brasília: MEC, 2016. Disponível em: <http://basenacionalcomum.mec.gov.br/>. Acesso em: 23 mar. 2017.

BRASIL. Ministério da Educação. Secretaria de Educação Básica. Diretrizes curriculares nacionais para a educação infantil. Brasília: MEC/SEB, 2010.

BRASIL. Ministério da Educação e do Desporto. Secretaria de Educação Fundamental. Referencial curricular nacional para a educação infantil. Brasília: MEC/SEF, 1998.

CASTRO, J.S. "Quando elas não querem mais ficar juntas fazendo, deixo elas pegarem brinquedos e brincarem": os atos docentes como promotores da brincadeira e da linguagem entre as crianças pequeninas. Trabalho apresentado no GT 07. Anais da 37 ${ }^{a}$ Reunião Científica da ANPEd, Florianópolis, 2015. Disponível em 
<http://www.anped.org.br/sites/default/files/poster-gt07-3978.pdf.>. Acesso em: 12 dez. 2017.

CASTRO, J. S. A constituição da linguagem entre os e dos bebês no espaço coletivo da educação infantil. Trabalho apresentado no GT 07. Anais da 36a Reunião Científica da ANPEd, Goiânia, set.-out. 2013.

CORSINO, P. (org.). Educação Infantil: cotidiano e políticas. Campinas: Autores Associados, 2009. (Coleção Educação Contemporânea).

COSTA, J.P. SANTOS, L. P. As múltiplas linguagens e a organização do trabalho pedagógico na educação infantil. Anais da VI Semana de Integração Inhumas: UEG, 2017, p. 715-732.

EDWARDS, C.; GANDINI, L.; FORMAN, G. (Org.) As cem linguagens da criança. Porto Alegre: Artmed, 1999.

FARIA, A.L.G.; FINCO, D. (Org.). Sociologia da Infância no Brasil. Campinas: Autores Associados, 2011.

FIORIO, A.F.C. Infância e educação: as crianças saíram da foto e entraram nas salas de aulas. Trabalho apresentado no GT 07. Anais as $\mathbf{3 3}^{\mathrm{a}}$ Reunião Anual da ANPEd, Caxambu/MG, 2010. Disponível em: < http://33reuniao.anped.org.br/internas/ver/trabalhos-gt07>. Acesso em 12 dez. 2017.

FREITAS, L.A.N. O espaço da linguagem musical na educação infantil segundo a abordagem de Reggio Emilia. Trabalho apresentado no GT 07. Anais da 37ª Reunião Científica da ANPEd, Florianópolis, 2015. Disponível em $<$ https://play.google.com/store/apps/details?id=dmx.appyou.anped37>. Acesso em: 12 dez. 2017.

LAVILLE, C.; DIONNE, J. A construção do saber: manual de metodologia da pesquisa em ciências humanas. Porto Alegre: Artmed; Belo Horizonte: UFMG, 1999. 
MACHADO, M.C.A. Educação infantil e sócio interacionismo In: OLIVEIRA, Z.M.R.(Org.) Educação infantil: Muitos olhares. 2 ed. São Paulo: Cortez, 1995.

NIGRIS, E.; NEGRI, S. C.; ZUCCOLI, F. (Org.). Esperienza e didática. Roma: Carocci, 2008.

RABELLO, E.T.; PASSOS, J.S. Vygotsky e o desenvolvimento humano. [S.I., s.d.]. Disponível em <http://www.josesilveira.com>. Acesso em: 28 out. 2017.

RINALDI, C. In dialogue with Reggio Emilia: Listening, researching and learning. London: Routledge, 2006.

ROURE, G. Q.. Infância, experiência, linguagem e brinquedo. Trabalho apresentado no GT 07. Anais as 33를 Reunião Anual da ANPEd, Caxambu/MG, 2010. Disponível em: < http://33reuniao.anped.org.br/internas/ver/trabalhos-gt07>. Acesso em 12 dez. 2017.

VIGOTSKI, Lev Semionovich. A construção do Pensamento e da Linguagem. São Paulo: Martins Fontes, 2000.

\section{APÊNDICE - NOTA DE RODAPÉ}

3. Neste trabalho, nos limitamos apenas a fazer referência à BNCC, sem desenvolver uma crítica a ela, considerando que o objetivo de nosso trabalho focalizou a importância e presença das linguagens.

Enviado: Abril, 2018.

Aprovado: Agosto, 2019.

RC: 35237

Disponível em: https://www.nucleodoconhecimento.com.br/educacao/multiplaslinguagens 